\title{
The Effectiveness of Using a Bilingualized Dictionary for Determining Noun Countability and Article Selection
}

\author{
Alice Yin Wa Chan, Department of English, City \\ University of Hong Kong, Hong Kong (enalice@cityu.edu.hk)
}

\begin{abstract}
This article discusses the use of a bilingualized dictionary, namely Oxford Advanced Learner's English-Chinese Dictionary 8 (OALECD8), by advanced Hong Kong Cantonese ESL learners in the determination of noun countability and associated article use. A homogenous group of 30 English majors in a local university participated in the study, which consisted of a noun countability and article selection task without and with the use of the dictionary. The results show that although bilingualized dictionaries are useful in helping learners determine noun countability and associated article use, learners often misinterpret dictionary information and model on inappropriate structures, resulting in article errors and/or wrong countability judgments. Chinese translations are also sometimes sources of errors. The results of the study provide lexicographers with signposts to the selection of noun information to be included in a learner's dictionary. More explicit information about noun countability and related article use should be provided in a more userfriendly arrangement. ESL teachers are also advised to engage advanced learners in analyses uncovering the different syntactic requirements of equivalent vocabulary items in the target and source languages when using a bilingualized dictionary.
\end{abstract}

Keywords: ENGLISH NOUN COUNTABILITY, ENGLISH ARTICLE SYSTEM, ARTICLE SELECTION, BILINGUALIZED DICTIONARIES, LEARNERS' DICTIONARIES, CANTONESE ESL LEARNERS, SECOND LANGUAGE ACQUISITION, EFFECTIVENESS OF DICTIONARIES

Opsomming: Die effektiwiteit van die gebruik van verklarende woordeboeke met 'n tweetalige dimensie om substantiewe se telbaarheid en lidwoordseleksie te bepaal. Hierdie artikel bespreek die gebruik van 'n verklarende woordeboek met vertalings ("bilingualized dictionary"), naamlik die Oxford Advanced Learner's EnglishChinese Dictionary 8 (OALECD8), deur gevorderde Hongkongse Kantonnese EVT-leerders vir die bepaling van die telbaarheid van substantiewe en die gepaardgaande lidwoordgebruik. 'n Homogene groep van 30 studente met Engels as hoofvak by 'n plaaslike universiteit het aan die studie deelgeneem, wat uit 'n taak bestaan het waar die telbaarheid van substantiewe bepaal en lidwoorde geselekteer moes word sonder en met die gebruik van 'n woordeboek. Die resultate toon dat, hoewel 'n verklarende woordeboek met vertalings nuttig is om leerders te help om die telbaarheid van substantiewe en die gepaardgaande lidwoorde te bepaal, leerders dikwels woordeboekinligting verkeerd interpreteer en op onvanpaste strukture baseer, wat tot lidwoordfoute en/of 
verkeerde besluite ten opsigte van telbaarheid lei. Chinese vertalings is ook soms die oorsaak van foute. Die resultate van die studie verskaf aanwysings aan leksikograwe vir die seleksie van inligting oor substantiewe wat in 'n aanleerderswoordeboek ingesluit behoort te word. Meer eksplisiete inligting oor die telbaarheid van substantiewe en die verwante gebruik van lidwoorde behoort in 'n meer gebruikersvriendelike ontwerp voorsien te word. EVT-onderwysers word ook aangeraai om gevorderde leerders analises te laat doen wat die verskillende sintaktiese vereistes van ekwivalente woordeskatitems in die doel- en die brontale ontbloot wanneer 'n verklarende woordeboek met vertalings gebruik word.

Sleutelwoorde: TELBAARHEID VAN ENGELSE SUBSTANTIEWE, LIDWOORDSTELSEL IN ENGELS, ARTIKELSELEKSIE, VERKLARENDE WOORDEBOEKE MET VERTALINGS, AANLEERDERSWOORDEBOEKE, KANTONNESE EVT-LEERDERS, TWEEDETAALVERWERWING, EFFEKTIWITEIT VAN WOORDEBOEKE

\section{Introduction}

The acquisition of English articles by second language learners has often been found to be a difficult process (Huebner 1983; Master 1987; Parrish 1987; Pica 1985; Thomas 1989; Murphy 1997; Robertson 2000; Zobl 1980), especially for learners whose native languages lack articles (Ionin, Zubizarreta and Maldonada 2008; Snape 2008), like Chinese. Article use with abstract nouns is even more difficult than with concrete nouns, resulting in more article errors (Hua and Lee 2005; Ogawa 2008). The intuitive judgment that learners make on the countability of a noun is important in affecting their use of articles with that noun, especially a/an vs. ZERO, and a direct link between learners' use of ZERO and their judgment of non-count nouns has been found in Yoon (1993). Learners' noun countability judgment, however, often deviates from native speaker norms. Many learners have a tendency to consider countability as a fixed or static property and assume that nouns are either countable or uncountable irrespective of context (Butler 2002), and there are learners who think that abstract nouns must be uncountable (Amuzie and Spinner 2013). However, Amuzie and Spinner (2013), following the claim of Allan (1980) that there are different levels of countability, argue that countability should better be treated as a nonbinary concept. Whether the perceptual system of noun countability that native English speakers use is "describable, explainable or acquirable by second language learners" (Yoon 1993: 284) is, thus, questioned. Deviant countability judgments often result in learner errors, such as the pluralization of uncountable nouns (e.g. advices, equipments), which has been argued in the literature as fairly common (Schneider 2011). Although there exist conflicting findings that the countable use of uncountable nouns is highly infrequent when compared with usage that matches native speaker norms (Hall, Schmidtke and Vickers 2013), ESL/EFL learners' difficulties with the use of English articles as a result of indeterminate noun countability are well-attested (Xue 2010). 


\section{Noun Countability in English}

Noun countability is one area in English which is most problematic, as the countability of an English noun is not so clear-cut: The countable/uncountable distinction is even described as "primarily arbitrary, unprincipled, or idiosyncratic" (Wisniewski, Lamb and Middleton 2003: 585). Although most English nouns are clearly countable (e.g. boy, girl) or uncountable (e.g. furniture, equipment), there are many nouns which may be countable or uncountable depending on their meaning (e.g. light, difficulty) (Greenbaum and Nelson 2009). It has even been argued in the literature that there is no absolute constraint which will prevent any nouns from functioning uncountably (Allan 1980; cited in Dziemianko 2012). Uncountable nouns are often described as nouns which can only be accompanied by determiners which do not refer to a distinction in number, such as possessives (e.g. their) and demonstratives (e.g. that) (Greenbaum and Nelson 2009), yet there are uncountable nouns which can be used with the indefinite article a/an (e.g. knowledge in a good knowledge of music, awareness in an awareness of the importance). ESL learners often find it difficult to understand why a certain English noun is mass instead of count, or vice versa (Lock 1996), as many nouns which are often perceived as countable by ESL learners (e.g. furniture) are in fact uncountable in English, and nouns which are often perceived as uncountable can be countable (e.g. water). Popular grammar books on the market, including those targeting university students, only give examples of clearly countable and uncountable nouns and explain the conditions, often in very general terms and with a few examples, under which uncountable nouns can be used as countable or vice versa. Other less common usages, such as the use of the indefinite article with an uncountable noun, is seldom, if at all, mentioned. As a result, other learning resources such as learners' dictionaries become important information providers especially when the usage of individual nouns is in question. As Lock (1996) argues, "learners need to have access to a good dictionary in which the different uses of nouns associated with any differences in their countability status are clearly marked" (p. 24), and with more use of learners' dictionaries, learners could identify the countability of a noun more correctly (Miller 2005). A good dictionary should show, therefore, the countable and uncountable usages of a noun clearly and be able to help learners differentiate the differences between the two usages, as it is the uses of a noun which should be classified into countable and uncountable rather than the noun itself (Tang 2006).

\section{Noun Countability Information in Learners' Dictionaries}

Although noun countability information is one important piece of information about nouns in learners' dictionaries (Chan and Loong 1999) and has been argued as a ready-made tool which can help learners "acquire one of the hardest grammatical features of the English language" (Miller 2006: 435), there are 
doubts about the usefulness of such information in learners' dictionaries. Xue (2010), for example, has observed that the lack of indication of what articles or quantifiers should be used before a noun, as well as discrepancies between the labels (e.g. uncountable) and usage examples (e.g. an education), limits the effectiveness of dictionary information in helping learners overcome their problems in noun countability.

A preliminary survey of popular learners' dictionaries used in Hong Kong confirms Xue (2010)'s observations. Different notations are used in different dictionaries for giving countability information. Some dictionaries (e.g. Oxford Advanced Learner's English-Chinese Dictionary 8 (OALECD8)) use symbols such as [C], [U], [sing.] and [pl.] for countable, uncountable, singular and plural nouns, respectively. Others (e.g. COBUILD4) use more elaborate notations such as $\mathrm{N}$-count, $\mathrm{N}$-count $\mathrm{usu}$. sing, $\mathrm{N}$-sing, $\mathrm{N}$-Var etc. While these notations are largely self-explanatory, the countability information given for a certain noun is sometimes equivocal. For example, the countability information given for the first sense of the word explanation in OALECD8 is [C, U] with about 10 examples, some of which use the target noun as a countable noun while others use it as uncountable with no indication which is which. It may be argued that the user's guide can help clarify the equivocal information using a general rule of thumb, yet a thorough reading of the explanatory notes and/or user's guides is not something that dictionary users will normally do (Chan 2005). What is more, the information and examples given in the guides may just be clear exemplars and cannot capture all possible scenarios. For example, OALECD8 only specifies, in the references section, that [sing] refers to nouns that are always singular and have no plural forms and such nouns are often used with a particular determiner. The example given as illustration is fillip, with the pattern (e.g. a fillip to/for sth) (Hornby 2013: R17). This may not be useful in helping learners distinguish the different usages of other words, such as choice, the second usage of which was specified as $[U$, sing]. Given that the only information provided in the sub-entry is the noun being uncountable or singular without any specifications about the use of a determiner, it is not clear if learners will know whether choice should be used with or without an article, The presentation of nouns as both countable and uncountable in learners' dictionaries may, therefore, result in confusion rather than assurance if there are no further specifications about the usage of the nouns in different contexts (Xue 2010). Whether learners can successfully retrieve the required information of a noun from a learner's dictionary, including noun countability and related article choices, is worth investigating.

\section{Objectives}

Given that Chinese does not have articles and the countability of an English noun is often different from that of its Chinese equivalent, it is interesting to investigate if the corresponding information provided in a bilingualized dic- 
tionary ${ }^{1}$ is useful enough for learners' judgment of English noun countability and related article use. The main objective of the study was to investigate how effective a bilingualized dictionary was in helping ESL learners determine the countability of English nouns and associated article use. In so doing, learners' problems in this aspect of language use, as well as the usefulness of Chinese translations in bilingualized dictionaries, would be revealed. As the most popular bilingualized dictionary used by advanced Hong Kong ESL learners is OALECD (Chan 2005), the latest edition available on the market at the time of the study, namely OALECD8 (Hornby 2013), was used for consultation.

\section{Methodology}

\section{Participants}

A homogenous group of 30 Cantonese university English majors from a local university were invited to participate in the study. Participant selection was based on convenience sampling. These included 8 males and 23 females. Their ages were from 19 years to 35 years at the time of the study. All of them were taking English as their majors. Three of them had learnt English for 14-16 years, and seventeen for 17-19 years, and the rest for 20 years or more. Twentyfour had received a $C$ or above in the Hong Kong Advanced Level Use of English (UE) ${ }^{2}$ exam, 7.5 or above in the International English Language Testing System (IELTS) test, or 5 or above in the Hong Kong Diploma of Secondary education (HKDSE) ${ }^{3}$, and the rest had received a D in HKALE, 7 in IELTS, 4 in HKDSE, or $\mathrm{C}$ in the Hong Kong Certificate of Education Examination (HKCEE). One had received a $\mathrm{C}$ in the General Certificate of Education (GCE) A-level examination. In view of their linguistic backgrounds, the participants could all be regarded as advanced ESL learners. Having many more female students than male students was inevitable, as there are many more female English majors than male English majors in Hong Kong (and probably worldwide).

Two male Cantonese university English graduates from a local university and two female Cantonese university English majors from another local university were invited to serve as a pilot group before the implementation of the actual study. Their ages were from 23 to 30 years of age. All of them had learnt English for 20 years or more. One had received a C, two had received a D, and one had received an E in HKALE respectively. Their linguistics backgrounds were deemed comparable to those of the participants.

\section{Target Nouns}

The present study targeted nouns which have varied uses in terms of countability and can be countable/singular/plural or uncountable depending on the context and/or the meaning of the word in that context. A research assistant, 
who graduated from an English programme in a local university and was doing a Master's degree in English in another local university, was responsible for selecting potential target nouns and sentence contexts from different online and paper dictionaries. These included Oxford Dictionaries Online (http:// www.oxforddictionaries.com/), Cambridge Dictionaries Online (http://dictionary. cambridge.org/), Collins COBUILD Advanced Learner's English Dictionary, 4th edition (Sinclair 2003), Oxford Collocations Dictionary for Students of English (Deuter, Greenan, Noble and Phillips 2002), and English-Chinese Learner's Thesaurus (Manser 2009). A total of 50 nouns (with different sentence contexts for each) which satisfied the criteria for inclusion in the study, were identified. From these, the researcher chose 14 for the pilot study based on her experience of ESL learners' use of the words as well as the research assistant's own report, as an English graduate, of his perception of the levels of difficulty of the use of the words with and without the help of a dictionary.

The characteristic of the target nouns can be seen by the word thought, which is uncountable when used in sentences such as "She doesn't give any thought to her appearance" (Cambridge Online) but plural in "If he wasn't there physically, he was always in her thoughts" (Sinclair 2003: 1508). Another example is the word ability, which is uncountable as used in "She utilizes her resources to the best of her ability" (Oxford Online), but countable as used in "She is a woman of considerable abilities" (Cambridge Online). The countability of these words in a certain context, whether an article should/can be used with these words in a certain context, and whether these words should be used in the plural form, if any, in a certain context, are all difficult to determine.

\section{Procedures}

The research assistant was responsible for implementing the task, which included a noun countability judgement task without and with the use of a dictionary and an introspective questionnaire for each target noun (see Noun Countability Task and Introspective Questionnaires), and giving initial instructions to the participants. A dictionary packet consisting of a scanned version of the introductory guide and the entries of the target nouns from OALECD8 was provided to each participant for consultation.

Before the implementation of the actual task, a draft version of the task sheet consisting of 14 nouns was piloted with the pilot group (see Participants). A total of 14 nouns (with three sentences each) were included in the pilot task. The whole pilot group found that the level of difficulty of the sentences was suitable for English majors and that the instructions were clear. Only some minor changes to the wording of the instructions of the task sheet and the introspective questionnaire were made to facilitate participants' understanding of the requirements. The nouns which were found to be relatively easy to the pilot group (e.g. with one or more sentences accurately completed by most or all of the pilot group participants without the use of a dictionary) were deleted, 
because it was thought that the use of a dictionary for such words was not very necessary. As a result, only seven nouns, including awareness, behavior, feeling, knowledge, reason, thought, understanding, were chosen for the actual task, and the majority of the participants spent about 1 to 1.5 hours on the completion of the task and the questionnaires.

\section{Noun Countability Task}

For each of the seven chosen nouns, three sentence contexts were given, at least one of which was a context in which the noun was used as an uncountable noun, and one in which the noun was used as a singular noun, a plural noun, or a countable noun. The third sentence context could be either. For each sentence context, a word group of which the target noun formed a part was deleted. The participants had to complete each sentence by (i) choosing the correct word group from among three given options and (ii) deciding whether the target noun was used as a countable noun or an uncountable noun in the sentence context. The first option was the target noun in a singular form without an article (e.g. problem behavior), the second option was the target noun in plural form without an article (e.g. problem behaviors), and the last option was the target noun in singular form with a/an (e.g. a problem behavior). The task consisted of two parts. The first part of the task was to be completed without the use of a dictionary. This tested the participants' performance without the help of any learning resources and their performance could reflect their initial response of the usage of the target nouns. The second part of the task was done with the use of OALECD8. The participants were required to use the relevant information given in the dictionary entries to help them make decisions about noun countability and related article use for each sentence context. The participants' performance in this part could reflect the effectiveness of the dictionary information they relied on.

Care was taken to ensure that the sentences included in the task were not identical to the examples given in OALECD8, so that the participants had to use their own discretion when choosing the most suitable option for a sentence. However, there were still some sentences or phrases which were very similar to those in OALECD8, such as There is a feeling of dissatisfaction with the government (Cambridge Online; cf. 3B in Appendix I) and a feeling of hunger/excitement/ sadness in OALECD8. Care was also taken to ensure that the context would not give hints to the countability of a target noun, so such items (e.g. a singular verb) were included as part of the options to be chosen. For example, for the sentence We had not set a date for marriage but there (Sinclair 2003: 1579; cf. 7B in Appendix I), the options included in the task were was understanding, were understandings and was an understanding, with the verbs included as part of the options. As such, no hints about the number of the target noun would be given, and the participants could not use any obvious cues (such as the incompatibil- 
ity of a mass noun with a plural verb or the incompatibility of a singular verb with a plural noun) to assist their selection.

Because the three options given for each sentence followed the same pattern (i.e. in singular form without an article, in plural form without an article, and in singular form with a/an), it was inevitable that some options were ungrammatical (e.g. intense awarenesses). The occasional inclusion of an ungrammatical option was deemed acceptable, given that the purpose of the task was to require participants to decide on the correct form of a noun (and its associated article use) in a certain context.

\section{Introspective Questionnaires}

Following a similar methodology employed in the literature (e.g. Chan 2012a, $2012 b$ ), after the completion of all the three sentences for each noun, the participants had to complete an introspective questionnaire. The objective of the introspective questionnaires was to gather information about how the information given in the dictionary helped them make their decisions. There were forced-choice questions asking participants from which part of the dictionary entry they found the information they wanted to look for, including English definitions, English examples, Chinese translations of definitions, Chinese translations of examples, codes/abbreviations, and special features such as bold or italics. There were also questions asking participants how they felt about their decisions on ending a search (i.e. they were sure that their decisions were correct, they were not sure if their decisions were correct, and they didn't think they got the relevant information from the dictionary). For participants who were sure that their decisions were correct, they were required to write out the definitions, examples etc. which led them to their decisions and describe how such definitions, examples, etc. showed them that their decisions should be correct. For those who were not sure that their decisions were correct, they were also asked to write out the definitions, examples etc. which led them to their decisions and say why they were doubtful about their decisions. For those who did not think that they could find the relevant information from the dictionary entries, they were asked to describe the difficulties they encountered during consultation and how they made their final decisions. All the participants were also asked to do six ranking questions asking them to rank the overall usefulness of the different kinds of information in doing a search, including English definitions, English examples, Chinese translations of definitions, Chinese translations of examples, codes/abbreviations, and special features (see Appendix II).

Although there were three sentences for each noun and participants may have relied on different pieces of information from the dictionary entries when making a decision about each sentence, to avoid the task being too time-consuming and draining, it was decided that only one questionnaire was used for 
each noun, so each participant had to do only a total of seven questionnaires and report seven dictionary consultations, resulting in a total of 210 (i.e. 30 participants $x 7$ nouns) questionnaires done by for the whole study. Clear instructions were given in the questionnaires requiring participants to specify clearly which definitions, etc. were for which sentence if different definitions, examples, etc. for the three sentence contexts were relied on.

\section{Data Analysis}

\section{Language Task: Article Selection and Countability Judgement}

The participants' choice of articles for each noun and their corresponding judgment of countability were recorded separately, so even if a correct article was chosen for the completion of a sentence yet the judgement of countability of the target noun was inaccurate, or vice versa, the performance could be reflected independently. This way of processing the language task resulted in a total of six verdicts for each noun (three for article selection and three for grammaticality judgment) for each participant.

- For both article selection and noun countability judgment, the number of correct choices made by the participants on each noun (all three uses), as well as that for the seven nouns together, was counted, and the corresponding accuracy rates were calculated.

- For the three article options (i.e. ZERO + singular, ZERO + plural (or a/an + singular $)^{4}$, and a/an + singular), the overall accuracy rate of each was obtained by calculating the total number of correct selections made for that article option out of the total number of target instances of that article option.

- For the two noun countability options (i.e. U or C), the overall accuracy rate of each was obtained in a similar fashion (i.e. calculating the total number of correct judgements made for that countability use out of the total number of target instances of that countability use).

\section{Introspective Questionnaires}

Because the introspective questionnaires consisted of both forced-choice questions and open-ended questions, both quantitative and qualitative analyses were performed accordingly.

- For the forced-choice question about participants' feeling on ending a search, the number of participants choosing a certain option (e.g. sure that the decision was correct) was counted and the percentage was calculated out of the total number of participants (i.e. 30). 
- For the questions about the overall usefulness of each kind of dictionary information, the number of instances that a certain option (e.g. very useful) was chosen was counted, and the corresponding percentage was calculated out of 210 (i.e. 30 participants $x 7$ nouns).

- Answers to the open-ended questions were tabulated and emerging patterns about the participants' problems in using dictionary information and/or strategies employed for problem solving, etc. were identified. The examples, definitions and/or other dictionary information which the participants based their decisions on were referred to when necessary. No quantitative analyses of the open-ended questions were done, as there was no attempt to compare learner problems and/or strategies.

\section{Statistical Analyses}

Proportion Z-tests using Excel 2013 were conducted to determine the significance of the differences in the participants' noun countability judgments and article selections without and with the use of a dictionary. A proportion Z-test is a test of the significance of the difference between two proportions from independent samples (Davis 1982). Assuming that the samples are normally distributed, if $Z$ ( $Z$-value) $>1.96$, then there is a significant difference between the two proportions at the 0.05 significance level. Otherwise, the difference can be attributed to sampling errors. Given that the results on countability judgements and article selections were calculated as correctness percentages, Proportion Z-tests were considered the most appropriate statistical analysis for comparison.

\section{Quantitative Results (Language Task and Introspective Questionnaires)}

Language Task: Performance on Article Selection without and with the Use of a Dictionary

The participants' overall performance on article selection showed a significant improvement from an overall accuracy rate of $47.6 \%$ without the use of a dictionary to an overall accuracy rate of $60.6 \%$ with the use of a dictionary ( $\mathrm{Z}=$ 4.63). However, when individual nouns were taken into consideration, only the improvements for awareness, behavior, knowledge and reason were statistically significant $(Z=2.24,4.37,2.71,3.22$ respectively). Although there were some numerical rises or drops for the other three nouns, the differences were not statistically significant (see Table 1).

The article selection accuracy rate rose from $44.3 \%$ to $51.3 \%$ when the target article was ZERO + singular and from $39 \%$ to $70 \%$ when the target article was a/an (+ singular) with the use of a dictionary. There was a numerical drop from $70.8 \%$ to $67.5 \%$ with the use of a dictionary for ZERO + plural. However, 
proportion Z-tests showed that only the improvement for a/an + singular was statistically significant $(Z=6.38)$ (see Table 1$)$.

Table 1: Language Task: Participants' performance on article selection without and with the use of a dictionary

\begin{tabular}{|c|c|c|c|c|}
\hline Noun & \multicolumn{2}{|c|}{ Article Selection Without a Dictionary } & \multicolumn{2}{|c|}{ Article Selection With a Dictionary } \\
\hline & Correct & Incorrect & Correct & Incorrect \\
\hline awareness & $43 / 90(47.8 \%)$ & $47 / 90(52.2 \%)$ & $58 / 90(64.4 \%)$ & $32 / 90(35.6 \%)$ \\
\hline behavior & $49 / 90(54.4 \%)$ & $41 / 90(45.6 \%)$ & $76 / 90(84.4 \%)$ & $14 / 90(15.6 \%)$ \\
\hline feeling & $56 / 90(62.2 \%)$ & $34 / 90(37.8 \%)$ & $55 / 90(61.1 \%)$ & $35 / 90(38.9 \%)$ \\
\hline knowledge & $42 / 90(46.7 \%)$ & $48 / 90(53.3 \%)$ & $60 / 90(66.7 \%)$ & $30 / 90(33.3 \%)$ \\
\hline reason & $18 / 90(20 \%)$ & $72 / 90(80 \%)$ & $38 / 90(42.2 \%)$ & $52 / 90(57.8 \%)$ \\
\hline thought & $39 / 90(43.3 \%)$ & $51 / 90(56.7 \%)$ & $51 / 90(56.7 \%)$ & $39 / 90(43.3 \%)$ \\
\hline understanding & $53 / 90(58.9 \%)$ & $37 / 90(41.1 \%)$ & $44 / 90(48.9 \%)$ & $46 / 90(51.1 \%)$ \\
\hline Total & $300 / 630(47.6 \%)$ & $330 / 630(52.4 \%)$ & $382 / 630(60.6 \%)$ & $248 / 630(39.4 \%)$ \\
\hline \multirow[t]{2}{*}{$\underline{\text { Target Article }}$} & \multicolumn{2}{|c|}{ Article Selection Without a Dictionary } & \multicolumn{2}{|c|}{ Article Selection With a Dictionary } \\
\hline & Correct & Incorrect & Correct & Incorrect \\
\hline ZERO + singular & $133 / 300(44.3 \%)$ & $167 / 300(55.7 \%)$ & $154 / 300(51.3 \%)$ & $146 / 300(48.7 \%)$ \\
\hline $\begin{array}{l}\text { ZERO + plural (or } \\
\text { a/an + singular) }\end{array}$ & $85 / 120(70.8 \%)$ & $35 / 120(29.2 \%)$ & $81 / 120(67.5 \%)$ & $39 / 120(32.5 \%)$ \\
\hline a/an + singular & $82 / 210(39 \%)$ & $128 / 210(61 \%)$ & $147 / 210(70 \%)$ & $63 / 210(30 \%)$ \\
\hline
\end{tabular}

Language Task: Performance on Countability Judgment without and with the Use of a Dictionary

The participants' performance on countability judgment showed an improvement from an overall accuracy rate of $57.1 \%$ without the use of a dictionary to an overall accuracy rate of $70.3 \%$ with the use of a dictionary. The difference was statistically significant $(Z=4.87)$. When individual nouns were taken into consideration, although improvement was shown for most nouns, again only the improvements for three words, namely, awareness, behavior and knowledge, were statistically significant $(\mathrm{Z}=4.54,4.5,3.95$ respectively). When the target countability was uncountable, the participants' judgement rose significantly from an overall accuracy rate of $52.9 \%$ to $75.1 \%$ with the use of a dictionary $(\mathrm{Z}=$ 6.94), whereas when the target countability was countable, the participants' judgement with the use of a dictionary did not show a statistically significant difference (see Table 2). 
Table 2: Language Task: Participants' performance on countability judgment without and with the use of a dictionary

\begin{tabular}{|c|c|c|c|c|}
\hline \multirow[t]{2}{*}{ Noun } & \multicolumn{2}{|c|}{ Countability Judgment Without a Dictionary } & \multicolumn{2}{|c|}{ Countability Judgment With a Dictionary } \\
\hline & Correct & $\underline{\text { Incorrect }}$ & Correct & Incorrect \\
\hline awareness & $67 / 90(74.4 \%)$ & $23 / 90(25.6 \%)$ & $88 / 90(97.8 \%)$ & $2 / 90(2.2 \%)$ \\
\hline behavior & $48 / 90(53.3 \%)$ & $42 / 90(46.7 \%)$ & $76 / 90(84.4 \%)$ & $14 / 90(15.6 \%)$ \\
\hline feeling & $54 / 90(60 \%)$ & $36 / 90(40 \%)$ & $55 / 90(61.1 \%)$ & $35 / 90(38.9 \%)$ \\
\hline knowledge & $71 / 90(78.9 \%)$ & $19 / 90(21.1 \%)$ & $88 / 90(97.8 \%)$ & $2 / 90(2.2 \%)$ \\
\hline reason & $31 / 90(34.4 \%)$ & $59 / 90(65.6 \%)$ & $39 / 90(43.3 \%)$ & $51 / 90(56.7 \%)$ \\
\hline thought & $42 / 90(46.7 \%)$ & $48 / 90(53.3 \%)$ & $51 / 90(56.7 \%)$ & $39 / 90(43.3 \%)$ \\
\hline understanding & $47 / 90(52.2 \%)$ & $43 / 90(47.8 \%)$ & $46 / 90(51.1 \%)$ & $44 / 90(48.9 \%)$ \\
\hline Total & $360 / 630(57.1 \%)$ & $270 / 630(42.9 \%)$ & $443 / 630(70.3 \%)$ & $187 / 630(29.7 \%)$ \\
\hline \multirow[t]{2}{*}{$\underline{\text { Target Countability }}$} & \multicolumn{2}{|c|}{ Countability Judgment Without a Dictionary } & \multicolumn{2}{|c|}{ Countability Judgment With a Dictionary } \\
\hline & $\underline{\text { Correct }}$ & Incorrect & Correct & $\underline{\text { Incorrect }}$ \\
\hline uncountable & $238 / 450(52.9 \%)$ & $212 / 450(47.1 \%)$ & $338 / 450(75.1 \%)$ & $112 / 450(24.9 \%)$ \\
\hline countable & $122 / 180(67.8 \%)$ & $58 / 180(32.2 \%)$ & $105 / 180(58.3 \%)$ & $75 / 180(41.7 \%)$ \\
\hline
\end{tabular}

Introspective Questionnaires: Participants' Feelings after a Search

The results of the introspective questionnaire showed that the use of a dictionary did not seem to be very helpful in participants' article selection and countability judgment processes. For five out of the seven target nouns, there were many more dictionary consultations which ended with participants not being sure whether their decisions were correct than the number of dictionary consultations with participants feeling sure that their decisions were correct. In total, only after $38.1 \%$ of the consultations $(n=210)$ were participants sure of their decisions, whereas over $58.1 \%$ of the dictionary consultations ended with participants feeling unsure about the correctness of their decisions, and the rest $(3.8 \%)$ ended with participants feeling that they didn't get the relevant information from the dictionary consulted. The difference between these two feelings was statistically significant $(Z=10.35)$ (see Table 3 ).

Table 3: Introspective Questionnaires: Participants' feelings on ending a search

\begin{tabular}{|l|l|l|l|}
\hline Noun & $\begin{array}{l}\text { A. Sure that my } \\
\text { decision was correct }\end{array}$ & $\begin{array}{l}\text { B. Not sure whether my } \\
\text { decision was correct }\end{array}$ & $\begin{array}{l}\text { C. I don't think I got the relevant } \\
\text { info from the dictionary }\end{array}$ \\
\hline awareness & $9 / 30(30 \%)$ & $19 / 30(63.3 \%)$ & $2 / 30(6.7 \%)$ \\
\hline behavior & $17 / 30(56.7 \%)$ & $12 / 30(40 \%)$ & $1 / 30(3.3 \%)$ \\
\hline feeling & $5 / 30(16.7 \%)$ & $22 / 30(73.3 \%)$ & $3 / 30(10 \%)$ \\
\hline
\end{tabular}




\begin{tabular}{|l|l|l|l|}
\hline knowledge & $17 / 30(56.7 \%)$ & $13 / 30(43.3 \%)$ & $0(0 \%)$ \\
\hline reason & $11 / 30(36.7 \%)$ & $17 / 30(56.7 \%)$ & $2 / 30(6.7 \%)$ \\
\hline thought & $7 / 30(23.3 \%)$ & $23 / 30(76.7 \%)$ & $0(0 \%)$ \\
\hline understanding & $14 / 30(46.7 \%)$ & $16 / 30(53.3 \%)$ & $0(0 \%)$ \\
\hline Total & $80 / 210(38.1 \%)$ & $122 / 210(58.1 \%)$ & $8 / 210(3.8 \%)$ \\
\hline
\end{tabular}

Introspective Questionnaires: Usefulness of Dictionary Information on Article Selection and Countability Judgment

With regard to the kinds of information that participants found most useful, consonant with what has been found in the literature (Chan 2012a), examples came first, which were found to be the most useful in $46.7 \%$ of the total number of consultations. Unlike the results of previous literature such as Chan (2011), codes and abbreviations came next. They were regarded as very useful in $43.8 \% \%$ of total number of consultations, just slightly lower than that for examples and much higher than that for English definitions (30\%). Chinese examples, on the other hand, were mostly thought to be of no use (35.7\%) (see Table 4).

Table 4: Introspective Questionnaires: The usefulness of different kinds of dictionary information

\begin{tabular}{|l|l|l|l|l|}
\hline Information & very useful & useful & of little use & of no use \\
\hline English definitions & $63 / 210(30 \%)$ & $111 / 210(52.9 \%)$ & $30 / 210(14.3 \%)$ & $6 / 210(2.9 \%)$ \\
\hline English examples & $98 / 210(46.7 \%)$ & $97 / 210(46.2 \%)$ & $14 / 210(6.7 \%)$ & $1 / 210(0.5 \%)$ \\
\hline Chinese definitions & $38 / 210(18.1 \%)$ & $85 / 210(40.5 \%)$ & $52 / 210(24.8 \%)$ & $35 / 210(16.7 \%)$ \\
\hline Chinese examples & $13 / 210(6.2 \%)$ & $50 / 210(23.8 \%)$ & $72 / 210(34.3 \%)$ & $75 / 210(35.7 \%)$ \\
\hline Codes \& abbreviations & $92 / 210(43.8 \%)$ & $79 / 210(37.6 \%)$ & $32 / 210(15.2 \%)$ & $7 / 210(3.3 \%)$ \\
\hline Special features & $52 / 210(24.8 \%)$ & $89 / 210(42.4 \%)$ & $49 / 210(23.3 \%)$ & $20 / 210(9.5 \%)$ \\
\hline
\end{tabular}

A careful comparison between participants' performance on the noun countability task and their responses on the introspective questionnaires showed that for cases where they were sure that their answers were correctly made with the use of a dictionary, many instances of their article selection and/or countability judgments were actually incorrect. A total of 80 dictionary consultations (out of $210 ; 38.1 \%$ ) ended with participants being sure that their answers were correct, yet 59 of those $(73.8 \%$ ) had one or more incorrect decisions made (there were three questions for each of the seven target nouns, with each question requesting two decisions to be made, one on article selection and one on countability judgment; see Noun Countability Task). If individual decisions were taken in consideration, a total of 148 decisions (out of $480 ; 30.8 \%$ ) were actually wrong 
despite participants being sure about their decisions. The words reason and understanding showed the poorest accuracy-confidence match, with all the decisions for all the questions being wrong despite participants' feeling sure about their decisions after dictionary consultation ${ }^{5}$.

\section{Qualitative Results (Introspective Questionnaires)}

\section{Problems Reported and Strategies Employed}

DISTINCTIONS BETWEEN VARIOUS USES OF A TARGET NOUN: A number of problems with dictionary information were reported in the introspective questionnaires about participants' use of a bilingualized dictionary for article selection and countability judgement. One prevalent problem was difficulties in discerning the subtle differences between the countable, uncountable and singular uses of a target noun even after reading relevant dictionary information, especially when the definitions/examples were quite similar to each other6:

After consulting the dictionary, I thought treating "awareness" as uncountable or singular was actually the same. I was wondering why the dictionary doesn't specify the two usages in two sections if they do make a difference. So. I encountered a problem about differentiating the countability of the word (Student 2);

Especially usage 6, the code at the beginning tells the user that "feeling" is uncountable with that specified meaning, but then after the first example sentence, there suddenly appears a prepositional phrase structure "for sb/sth" followed by an example demonstrating a countable usage. This really made me confused (Student 2).

ACCEPTABILITY OF AN ARTICLE: Another major problem was difficulties in deciding whether an article was acceptable or needed in a certain context. For nouns that were marked as singular in the dictionary, such a problem was more widespread.

\section{It's hard to determine when to put an article before the noun (Student 15);}

"Awareness" is not something tangible, so I feel awkward when it can go with "an" together (Student 24; after reading a dictionary example showing "an awareness");

Even though the dictionary says that it should be singular, I'm not sure if the article " $a$ " should be included or not (Student 21);

ADEQUACY OF DICTIONARY EXAMPLES: There were concerns about the adequacy of examples when participants could not find enough examples for them to base their decisions on, yet occasionally the presence of too many definitions / examples, or too many usages of the same noun, also resulted in confusion: 
There isn't an example in the dictionary that fully explains both [U] and [C], like when do we use [U]/[C] (Student 16);

I didn't know why for usage 2, the dictionary doesn't show any examples of the plural form of "understanding" to show clearly when the word is treated as a countable noun instead of [usually singular] (Student 2);

There are too many definitions, as well as examples, which confuse me (Student 26);

Hard to distinguish between the three English definitions of "knowledge" (Student 27);

Not sure if it is countable or uncountable because the dictionary shows both for that definition (Student 22).

STRATEGIES EMPLOYED IN MAKING DECISIONS: When participants thought that they could not find the relevant information from the dictionary or were doubtful about the usefulness/appropriateness of dictionary information, strategies such as guessing, or using intuition and/or elimination were employed.

I used my intuition (Student 29);

By reading the definitions again and guessing (Student 26).

Sometimes they based their decision on their own understanding of the word and their previous encounters instead of on the dictionary entry or by guessing.

Based on my own understanding of the word and my observation. I don't think I have seen the plural form of "behavior" (Student 24);

I think there are many different problems and good behaviors of a child. There could be a "s" after behavior (Student 19).

Occasionally Chinese was used as the basis of decisions. This strategy was employed when participants thought that the difference in meaning resulted in different countability based on the countability of the corresponding Chinese nouns.

The Chinese definition of the first (感覺) and the third (情感) clarified the difference (i.e. the former more physical and senses while the latter focusses on how the heart feels) (Student 23);

All I knew is just that if "feeling" means "感覺", then it is countable. However, I was still not sure whether I could say "feelings of dissatisfactory" (Student 2).

\section{Unnoticed Problems}

The previous section revealed the problems that participants reported that they had encountered, leading to their uncertainty of the accuracy of their choices. Those were the problems that they themselves were aware of. However, careful scrutiny of the introspective reports showed that some participants had misun- 
derstood, misread or been misled by certain dictionary information, resulting in inaccurate countability judgement and/or article selection they were not aware of. This section will examine these unnoticed problems ${ }^{7}$.

CO-OCCURRENCE OF A/AN WITH AN UNCOUNTABLE NOUN: One prevalent problem was participants' unawareness of the acceptability of the co-occurrence of a/an with an uncountable noun in certain contexts. This misconception was often reinforced by the $[U]$ code found in the dictionary entry, despite the fact that [sing] was sometimes also given in the same dictionary entry to show another use of the noun. The following reports on the word knowledge, where participants chose limited knowledge instead of a limited knowledge in He has a limited knowledge of French (Cambridge Online) and/or intimate knowledge instead of an intimate knowledge in She has an intimate knowledge of the Asian market (Deuter et al 2002), demonstrate this.

It must be [U] (from the dictionary). There are no countable nouns, so I can eliminate the others (Student 12);

It shows that "knowledge" is uncountable (Student 14);

No matter which meaning it carries, there's no way for it to be countable (Student 24).

Interestingly, there were also cases when participants were misled that a/an could always be used for uncountable nouns which could also be used as singular nouns. An example can be seen from the word awareness, which was shown in the dictionary as $[U, \operatorname{sing}]$. There were a number of examples showing the use of the word with an (e.g. an awareness of the importance of eating a healthy diet; develop an awareness of how the Internet can be used.; an increasing awareness of sth; a general awareness that this is not the solution (Hornby 2013: 121)). Therefore, many participants, after reading the examples with the co-occurrence of an with the target noun, thought that the indefinite article was needed in all contexts without being aware of the examples which suggested otherwise (e.g. complete lack of awareness of the issues involved; environmental awareness; energy awareness week (ibid: 121)).

When I look at those examples on the dictionary as noun phrases, it always has an article (a/an) in front of how awareness is described (Student 8);

Now I realize the nature of the word, awareness, that it is an uncountable singular noun. Option C could be eliminated and an article is needed (Student 11);

Because in the dictionary entries, there is usually an article before awareness. Except for "lack of awareness", the rest in those examples is followed by an article at the beginning (Student 20).

RELATED WORDS/PHRASES IN DICTIONARY EXAMPLES AND TARGET SENTENCE: A related word in a dictionary example or definition sometimes triggered an 
inappropriate comparison and misled participants into thinking that the contexts of the target sentence (in the noun countability task) and the dictionary sentence(s) were the same and the latter could be appropriately used as a model. A case in point was the phrase "with reason" in the dictionary example She complained with reason (= rightly) (ibid: 1708), which was taken as a model for validating participants' inappropriate selection of ZERO for the phrase *without justified reason in the sentence Their goal is simply to cause terror without a justified reason (Oxford Online; see Appendix I) on the basis of the similarity between with reason and without (a) justified reason. The difference in meaning, and thus difference in article use, between the two phrases escaped participants' notice.

Another example of inappropriate correspondence made between two similar phrases was feeling, where a nasty feeling in the example I had a nasty feeling that we were lost (Hornby 2013: 761) was used as a model to confirm participants' choice of $a$ for *a genuine feeling in the sentence It all feels so lacking in genuine feeling (Oxford Online; see Appendix I).

\section{Sentence 5C resembles the example "She complained with reason (= rightly), so it should be "justified reason" (Student 11); \\ Genuine is an adjective while nasty is also adjective so same rule should be applied (Student 20).}

INFLUENCE OF CHINESE TRANSLATIONS: Chinese translations of dictionary definitions/examples were also sometimes sources of problems. Participants who thought that a target English phrase should best be translated into a certain Chinese equivalent were inclined to model their construction on corresponding English dictionary examples/definitions. Student 12, who (mistakenly) thought that the Chinese phrase 理性 (the power of the mind to think in a logical way, to understand and have opinions, etc. (Hornby 2013: 1708)) should best represent the meaning of reason in the target sentence Their goal is simply to cause terror without a justified reason (Oxford Online; see Appendix I), chose ZERO instead of $a$ for a justified reason on the basis of the dictionary example (i.e. Only human beings are capable of reason (Hornby 2013: 1708)) given for that definition of the target noun. Similarly, Student 8 chose thoughts (a person's mind and all the ideas that they have in it when they are thinking (ibid: 2176)) instead of thought for the sentence She doesn't give any thought to her appearance (Cambridge Online; see Appendix I) based on the English example My thoughts turned to home (Hornby 2013: 2176) of the Chinese definition 心思; 思想. A similar problem was seen with the article selection and countability judgment of the word understanding by Student 26 (details omitted).

The definition of 理性 make me choose it (Student 12);

It is clear that Question A is '心思; 思想' (Student 8); 
As I know, from the Chinese translations of definitions, the agreement "劦議" is suitable in this sentence, so option $c$ is correct (Student 26).

\section{Discussion}

The results of the study show that although learners may be aware of the importance of contexts on word usage and that different senses of the same word may be associated with different linguistic structures (Chan 2012a), they may not possess the ability to identify the correct sense of a target noun in a certain context so as to determine the countability of the noun and/or its associated article use. The results that no significant improvements were found in the participants' noun countability and/or related article use judgements of many target nouns after dictionary consultation also confirm the researcher's speculation that noun countability information in learners' dictionaries may not be useful. Though learners are sometimes aware of the inadequacy of dictionary entries and their difficulties in interpreting relevant dictionary information, many of their interpretation problems go unnoticed or even reinforced by their dictionary consultation processes. The different structures associated with the countable and uncountable uses of an English noun, as well as why and how they are different, are not always well explained or apparent in learners' dictionaries. A detailed look at some dictionary entries may help explain this.

In the middle of the dictionary entry for the target noun awareness after the syntactic specifications $([U, s i n g], \sim($ of $s t h), \sim($ that...)) and English and Chinese definitions, some example phrases/sentences (and their Chinese translations) are given, including

(1) an awareness of the importance of eating a healthy diet ${ }^{8}$,

(2) There was an almost complete lack of awareness of the issues,

(3) It is important that students develop an awareness of how the Internet can be used

(4) to raise/heighten/increase public awareness of sth,

(5) a greater/a growing/an increasing awareness of sth (Hornby 2013: 121).

It can be seen that some examples use the target noun as a singular noun with an (example 1), and others as an uncountable noun with ZERO (example 2), yet all examples follow the syntactic specifications of having a post-modifier with of, showing that the presence of a post-modifier does not impact on its countability. It is not clear whether a pre-modifier will have any effects on the countability of the noun, as there are both examples of singular and uncountable uses without a pre-modifier (examples 1-3), as well as examples of singular and uncountable uses with a pre-modifier (examples 4-5). Learners will be left to wonder whether a pre-modifier like public (example 4) is different from growing/increasing (example 5), and what the difference between them is, if any. It is also not clear whether the target noun used as a direct object of a transitive 
verb (e.g. to raise public awareness; example 4) is always uncountable. The meaning of the target noun does not seem to have an impact on countability either, as all the examples are grouped under the same sense, and only one single sense of the word is given in the dictionary entry. It is, thus, not difficult to understand how and why learners may be led astray by noun countability information in dictionary entries, resulting in misinterpretations and encoding problems.

As for the usefulness of Chinese translations, although there are no articles in Chinese and the concepts of countability in English and Chinese differ, Chinese translations in a bilingualized dictionary do play a role in Chinese ESL learners' noun countability and/or article selection determination. Their role is manifested in learners' modelling on the syntactic structure of an English definition/example with a Chinese translation which is thought to best represent the meaning of a target noun in a certain context. The strategy can be proceduralized as follows:

For a certain sentence context $(\mathrm{C})$ which motivates dictionary consultation, learners will

(i) identify the most suitable Chinese translation for the target English word,

(ii) locate an English example/definition given for that chosen Chinese translation,

(iii) model on the syntactic structure of the English example/definition;

(iv) insert the target English word with the associated syntactic structure in the dictionary example/definition into the sentence context (C).

While a translation in a bilingualized dictionary (e.g. Chinese) is preferably insertable in a target sentence of the same language (i.e. Chinese) (Gauton 2008), such a strategy of inserting a corresponding English phrase (based on the Chinese translation) into an English sentence is apparently not an appropriate dictionary consultation strategy. Very few equivalent words in two languages have precisely the same meanings. Two different languages may also have different syntactic requirements (e.g. verb transitivity) for corresponding vocabulary items or different syntactic patterns "to determine certain aspects of experience" (Gauton 2008:112), so the context for which a Chinese word is appropriate may not be a suitable context for the corresponding English phrase, or vice versa. These meaning and usage discrepancies are not usually reflected in the Chinese translations in an English-Chinese bilingualized dictionary, so learners who rely on a Chinese translation equivalent for the syntactic requirements of a target English word will likely encounter problems. Despite the usefulness of translations for decoding purposes (Cowie 1999), our results show that they are not equally useful for encoding. Where the source and target languages differ in a certain aspect of grammar, such as noun countability, translations in another language may even undesirably affect learners' 
encoding performance, providing illusive confirmation for learners' incorrect language choices like what have been observed in the present study.

\section{Implications}

The problems identified in the present study have important pedagogical and lexicographical implications. They inform ESL teachers and lexicographers of learners' dictionary consultation problems not just in the area of noun countability and/or article selection but also of the possible negative impacts of translations in bilingualized dictionaries on encoding. Given that article use is often regarded by ESL teachers as their students' number one difficulty (Covitt 1976; cited in Celce-Murcia and Larsen-Freeman 1983), it is important for ESL teachers to design suitable teaching programmes to help remedy the problems. Although it has been argued that learners may be able to learn the English article system better via exposure to the input (Lightbown and Spada 2013), explicit linguistic analyses using ample authentic data and relevant metalanguage should also be useful (Chan 2016). Exercises similar to the noun countability task used in the present study can be designed for an advanced ESL classroom to alert learners to the variability of noun countability and related article use as well as the importance of the context in making relevant judgements. Teachers can then engage learners in awareness raising discussions to explore the differences in the meanings of a target noun resulting from the use of a different article (ZERO inclusive) and/or different countability. It is also advisable for ESL teachers to alert learners to the different (or similar) syntactic requirements of equivalent vocabulary items in two languages when using a bilingualized dictionary. While both exposure to the input and explicit teaching are needed, the use of learners' dictionaries is also essential for noun countability and article use judgments, so it is advisable that ESL teachers encourage learners to make full use of such self-learning resources and introduce relevant dictionary skills training. However, they should also be made aware of the possible traps that they may fall into. Dictionary skills training programmes for advanced ESL learners can incorporate a metalinguistic analysis component where learners are engaged in activities in discovering such differences (or similarities) and the varied functions of dictionary information for encoding and for decoding.

Learners' dictionaries, being the most important self-learning resources, are indispensable in such teaching programmes. However, the information in learners' dictionaries about the syntactic environments and/or semantic specifications which impact on the countability of a noun and its associated article use is not user-friendly enough and needs refinement, as dictionary information has to result in correct language production if it is to be user-friendly for encoding (Dziemianko 2006). Lexicographers are recommended to improve the arrangement of relevant dictionary entries and include user-friendly information to facilitate learners' understanding and advance their language produc- 
tion. For dictionaries which use notations such as [C, U] or [U, sing] in the same sub-entry of a noun (e.g. OALECD), the subtle differences between the countable and uncountable uses of the target noun have been made indistinguishable. Such notations are better replaced by separate countability notations. At least one example sentence should be given for a context which triggers a different countability and/or related article use. The contexts under which a usually uncountable noun (e.g. knowledge) can be used as a singular noun with an article (e.g. a knowledge of) should better be specified clearly using guiding information. For example, while OALECD8 does give an example sentence (He has a wide knowledge of painting and music (Hornby 2013: 1157)) with a/an used with the word knowledge after the guiding phrase knowledge of/about sth, there is no clear indication when a/an can be used with the target word. With a clear guiding note such as "can be used with a/an in patterns like a/an (adj) knowledge of/about", then the contexts in which an article is allowed will become more salient and apparent.

\section{Conclusion}

In this paper, I have reported on the results of a noun countability determination and article selection task without and with the use of a bilingualized dictionary. It is found that noun countability is indeed a problematic area even for advanced ESL learners. Although noun countability information and examples of associated article use are included in a bilingualized dictionary, the amount of information included is not necessarily adequate in capturing the subtlety of this aspect of English grammar. The distinction between the meaning of a noun in a certain context and its meaning in another context is often not clearly presented, so the subtle differences between the countable and uncountable uses of many nouns are difficult for learners to discern, and misinterpretation or misapplication of dictionary information often results. The dictionary consultation problems identified in the present study can be grave, as revealed by participants' unawareness of their article mis-selections and/or countability misjudgments and their confidence in the "accuracy" of their decisions. Given that learners' dictionaries are widely accepted as useful self-learning resources, errors resulting from misreading/misinterpretation of dictionary information will often go unnoticed and may even be firmly ingrained in learners' minds, especially when there are superficially equivalent or similar structures mistakenly taken as models for production. Our results provide lexicographers with signposts to the selection and arrangement of noun information to be included in a learner's dictionary. It is important for lexicographers to anticipate the potential problems that learners have in interpreting noun countability judgment and/or related article use, so more explicit information should be provided in a more user-friendly manner to enable learners to unlock the variations in the structures related to the different countability of a noun. 


\section{Acknowledgements}

The work described in this article was fully supported by the Hong Kong Research Grants Council (Project Number: CityU 11400614). The support of the council is acknowledged. I would also like to thank all the participants for their participation, my research assistants for their administrative help, and the consultants in the City University Statistical Consulting Unit for their expert advice on statistical analyses.

\section{Endnotes}

1. A bilingual dictionary relates the vocabularies of two languages (e.g. English and Chinese) together simply by means of translation equivalents (Hartmann and James 1998). A bilingualized dictionary (e.g. OALECD) is a dictionary whose entries have been translated in full or in part into another language. Definitions and examples in both the target and source languages are included (see also Hartmann 1994; James 1994; Marello 1998).

2. The Hong Kong Advanced Level Use of English (UE) examination aimed to test students' ability to understand and use English at a level required for tertiary education and/or for future employment. (http://www.hkeaa.edu.hk/DocLibrary/HKALE/Subject_and_Syllabuses /2013/2013as-e-ue.pdf). It was normally taken by F.7 students in Hong Kong who had completed their two-year matriculation studies. UE Grade E was regarded as equivalent to Grade $E$ in the GCE A level examinations.

3. The Hong Kong Diploma of Secondary Education examination aims to measure the attainment of students upon their completion of six years of secondary education and has been the only public examination in the new 3-3-4 education system in Hong Kong since 2012. $5^{* *}$ is the highest grade that students can attain for a certain subject, followed by $5^{*}$ and 5 .

4. For target nouns which were used countably, sometimes more than one answer (both ZERO + plural and a/an + singular) was acceptable. For example, it is acceptable to say "There are feelings of dissatisfaction ...." or "There is a feeling of dissatisfaction.....".

5. The purpose of this paragraph is to identify possible problems with dictionary information, so corresponding data when participants were not sure whether their decisions were correct and those when they thought they could not find the relevant information from the dictionary are not reported.

6. All the introspective reports included in this section were given by participants who were not sure whether their decisions were correct after dictionary consultation, or those who didn't think they got the relevant information from the dictionary.

7. All the introspective reports included in this section were given by participants who were sure that their decisions were correct after dictionary consultation but who had made inappropriate article choices and/or countability judgments.

8. The numbers before the example sentences/phrases are not given in the OALECD8. They are just given in this paper for clarity purposes.

9. The sources of the sentences are given in the appendix for acknowledgement. They were not included in the task sheets given to the participants. The items in bold represent the versions given by the cited dictionaries, but alternative answers may be acceptable for some sentences. 


\section{References}

\section{Dictionaries}

Deuter, M., J. Greenan, J. Noble and J. Phillips. 2002. Oxford Collocations Dictionary for Students of English. Oxford: Oxford University Press.

Hornby, A.S. 2013. Oxford Advanced Learner's English-Chinese Dictionary. Eighth edition. Hong Kong: Oxford University Press.

Manser, M.H. 2009. English-Chinese Learner's Thesaurus. Hong Kong: Commercial Press.

Sinclair, J. 2003. Collins COBUILD Advanced Learner's English Dictionary. Fourth edition. Glasgow: HarperCollins.

http://dictionary.cambridge.org/. Retrieved on 17/10/2016.

http://www.oxforddictionaries.com/. Retrieved on 17/10/2016.

\section{Other Literature}

Allan, K. 1980. Nouns and Countability. Language 56(3): 541-567.

Amuzie, G.L. and P. Spinner. 2013. Korean EFL Learners' Indefinite Article Use with Four Types of Abstract Nouns. Applied Linguistics 34(4): 415-434.

Butler, Y.G. 2002. Second Language Learners' Theories on the Use of English Articles: An Analysis of the Metalinguistic Knowledge Used by Japanese Students in Acquiring the English Article System. Studies in Second Language Acquisition 24: 451-480.

Celce-Murcia, M. and D. Larsen-Freeman. 1983. The Grammar Book. An ESL/EFL Teacher's Course. Rowley, MA: Newbury House.

Chan, A.Y.W. 2005. Tactics Employed and Problems Encountered by University English Majors in Hong Kong in Using a Dictionary. Applied Language Learning 15(1-2): 1-28.

Chan, A.Y.W. 2011. Bilingualized or Monolingual Dictionaries? Preferences and Practices of Advanced ESL Learners in Hong Kong. Language, Culture and Curriculum 24(1): 1-21.

Chan, A.Y.W. 2012a. The Use of a Monolingual Dictionary for Meaning Determination by Advanced Cantonese ESL Learners in Hong Kong. Applied Linguistics 33(2): 115-140.

Chan, A.Y.W. 2012b. Cantonese ESL Learners' Use of Grammatical Information in a Monolingual Dictionary for Determining the Correct Use of a Target Word. International Journal of Lexicography 25(1): 68-94.

Chan, A.Y.W. 2016. How Much do Cantonese ESL Learners Know About the English Article System? System 56: 66-77.

Chan, A.Y.W. and Y. Loong. 1999. Establishing Criteria for Evaluating a Learner's Dictionary. Berry R., B. Asker, K. Hyland and M. Lam (Eds.). 1999. Language Analysis, Description and Pedagogy: 298-307. Hong Kong: Hong Kong University of Science and Technology.

Covitt, R. 1976. Some Problematical Grammar Areas for ESL Teachers. M.A. in TESL Thesis. Los Angeles: University of California.

Cowie, A.P. 1999. English Dictionaries for Foreign Learners: A History. Oxford: Clarendon Press.

Davis, L.M. 1982. American Social Dialectology: A Statistical Appraisal. American Speech 57(2): 83-94.

Dziemianko, A. 2006. User-friendliness of Verb Syntax in Pedagogical Dictionaries of English. Lexicographica Series Maior 130. Tübingen: Niemeyer. 
Dziemianko, A. 2012. Noun and Verb Codes in English Monolingual Dictionaries for Foreign Learners: A Study of Usefulness in the Polish Context. Poznań: Wydawnictwo Naukowe UAM.

Gauton, R. 2008. Bilingual Dictionaries, the Lexicographer and the Translator. Lexikos 18: 106-118.

Greenbaum, S. and G. Nelson. 2009. An Introduction to English Grammar. Third edition. Harlow: Pearson Longman.

Hall, C.J., D. Schmidtke and J. Vickers. 2013. Countability in World Englishes. World Englishes 32(1): 1-22.

Hartmann, R.R.K. 1994. Bilingualised Versions of Learner's Dictionaries. Fremdsprachen Lehren und Lernen 23: 206-220.

Hartmann, R.R.K. and G. James. 1998. Dictionary of Lexicography. London/New York: Routledge.

Hua, D. and T.H.-T. Lee. 2005. Chinese ESL Learners' Understanding of the English Count-Mass Distinction. Dekydtspotter, L., R.A. Sprouse and A. Liljestrand (Eds.). 2005. Proceedings of the 7th Generative Approaches to Second Language Acquisition Conference, April 15-18, 2004, Indiana University Bloomington: 138-149. Somerville, MA: Cascadilla Proceedings Project.

Huebner, T. 1983. A Longitudinal Analysis of the Acquisition of English. Ann Arbor: Karoma.

Ionin, T., M.L. Zubizarreta and S.B. Maldonado. 2008. Sources of Linguistic Knowledge in the Second Language Acquisition of English Articles. Lingua 118: 554-576.

James, G. 1994. Towards a Typology of Bilingualized Dictionaries. James, G. (Ed.). 1994. Meeting Points in Language Studies: A Festschrift for Ma Tailai. Working Papers: 184-196. Hong Kong: Hong Kong University of Science and Technology Language Center.

Lightbown, P.M. and N. Spada. 2013. How Languages are Learned. Fourth edition. Oxford: Oxford University Press.

Lock, G. 1996. Functional English Grammar: An Introduction for Second Language Teachers. Cambridge: Cambridge University Press.

Marello, C. 1998. Hornby's Bilingualized Dictionaries. International Journal of Lexicography 11(4): 292-314.

Master, P. 1987. A Cross-linguistic Interlanguage Analysis of the Acquisition of the English Article System. Unpublished Ph.D. Thesis. Los Angeles: University of California.

Miller, J. 2005. Most of ESL Students Have Trouble with the Articles. International Education Journal. ERC2004 Special Issue 5(5): 80-88.

Miller J. 2006. An Investigation into the Effect of English Learner's Dictionaries on International Students' Acquisition of the English Article System. International Education Journal 7(4): 435-445.

Murphy, S. 1997. Knowledge and Production of English Articles by Advanced Second Language Learners. Ph.D. Thesis. Austin: University of Texas.

Ogawa, M. 2008. The Acquisition of English Articles by Advanced EFL Japanese Learners: Analysis Based on Noun Types. Journal of Language and Culture 3: 133-151.

Parrish, B. 1987. A New Look at Methodologies in the Study of Article Acquisition for Learners of ESL. Language Learning 37: 361-383.

Pica, T. 1985. The Selective Impact of Classroom Instruction on Second-Language Acquisition. Applied Linguistics 6(3): 214-222.

Robertson, D. 2000. Variability in the Use of the English Article System by Chinese Learners of English. Second Language Research 16(2): 135-172.

Schneider, E.W. 2011. English Around the World: An Introduction. Cambridge: Cambridge University Press. 
Snape, N. 2008. Resetting the Nominal Mapping Parameter in L2 English: Definite Article Use and the Count-Mass Distinction. Bilingualism: Language and Cognition 11(1): 63-79.

Tang, E.Y. 2006. Linguistic Environment as a Determinant of English Countability. Proceedings of the 11th Conference of Pan-Pacific Association of Applied Linguistics: 266-280. Retrieved from http://www. paaljapan.org/resources/proceedings/PAAL11/pdfs/22.pdf.

Thomas, M. 1989. The Acquisition of English Articles by First- and Second-Language Learners. Applied Psycholinguistics 10: 335-355.

Wisniewski, E.J., C.A. Lamb and E.L. Middleton. 2003. On the Conceptual Basis for the Count and Mass Noun Distinction. Language and Cognitive Processes 18(5/6): 583-624.

Xue, M. 2010. Countable or Uncountable? That is the Question - Lexicographic Solutions to Nominal Countability in Learner's Dictionaries for Production Purposes. Lexikos 20: 540-558.

Yoon, K.K. 1993. Challenging Prototype Descriptions: Perception of Noun Countability and Indefinite vs. Zero Article Use. IRAL 31(4): 269-289.

Zobl, H. 1980. The Formal and Developmental Selectivity of L1 Influence on L2 Acquisition. Language Learning 30(1): 43-57.

http://www.hkeaa.edu.hk/DocLibrary/HKALE/Subject_and_Syllabuses/2013/2013as-e-ue.pdf. Retrieved on 17/10/2016. 


\section{Appendix I}

\section{Noun Countability Task}

For each of the following nouns, you need to

i. decide how the noun should be used in each of the given three sentences by choosing the most appropriate answer from the given options and writing the answer (e.g. a, or $\mathrm{b}$, or c) in the blank;

ii. decide whether the noun is used as a countable noun (C) or an uncountable noun (U) in each of the three sentences by circling the appropriate answer (i.e. $\mathrm{C}$ or $\mathrm{U}$ ) after each.

1. awareness

A. The body is an organism with of itself (Oxford Online). ${ }^{9}$

$\mathrm{C} / \mathrm{U}$
a. intense awareness
b. intense awarenesses
c. an intense awareness

B. Politicians now have of these problems (Deuter et al. 2002: 49).

a. much greater awareness

b. much greater awarenesses

c. a much greater awareness

C. She always seems to have of her sidekick status (Oxford Online).

$\mathrm{C} / \mathrm{U}$
a. affecting awareness
b. affecting awarenesses
c. an affecting awareness

2. behavior

A. Teachers can't always respond effectively to (Deuter et al. 2002: 62). C/U
a. problem behavior
b. problem behaviors
c. a problem behavior

B. Children should be rewarded for (Manser 2009: 34)

a. good behavior

b. good behaviors

c. a good behavior

C. These eating patterns are
a. learned behavior
b. learned behaviors
c. a learned behavior

3. feeling

A. It all feels so lacking in (Oxford Online). , genuine emotion, genuine interest
a. genuine feeling
b. genuine feelings
c. a genuine feeling 
B. There of dissatisfaction with the government (Cambridge Online).
a. is feeling
b. are feelings
c. is a feeling

C. It's incredible that Peter can behave with such stupid lack of

(Sinclair 2003: 526).
a. feeling
b. feelings
c. a feeling

4. knowledge

A. All of these plans require ___ in order to carry out the operation in a timely and accurate manner (Oxford Online).
a. insider knowledge
b. insider knowledges
c. an insider knowledge

B. He has of French (Cambridge Online).
a. limited knowledge
b. limited knowledges
c. a limited knowledge

C. She has of the Asian market (Deuter et al. 2002: 446).
a. intimate knowledge
b. intimate knowledges
c. an intimate knowledge

5. reason

A. They had to believe that there could be trouble (Sinclair 2003: 1192).
a. reason
b. reasons
c. a reason

B. The police have to believe that he is guilty (Cambridge Online).
a. reason
b. reasons
c. a reason

C. Their goal is simply to cause terror without
a. justified reason
b. justified reasons
c. a justified reason

6. thought

A. She doesn't give any to her appearance (Cambridge Online).
a. thought
b. thoughts
c. a thought

B. Alice had been so deep in that she had walked past her car without even seeing it (Sinclair 2003: 1508).
a. thought
b. thoughts
c. a thought 
C. If he wasn't there physically, he was always in (Sinclair 2003: 1508). C/U
a. her thought
b. her thoughts
c. a thought

7. understanding

A. They have to have of computers in order to use the advanced technology (Sinclair 2003: 1579).

a. basic understanding

b. basic understandings

c. a basic understanding

B. We had not set a date for marriage but there between us (Sinclair 2003: 1579).

a. was understanding

b. were understandings

c. was an understanding

C. There between Wilson and myself (Sinclair 2003: 1579).

$\mathrm{C} / \mathrm{U}$
a. was complete understanding
b. were complete understandings
c. was a complete understanding 


\section{Appendix II}

\section{Introspective Questionnaire \\ (for Part II of the Noun Countability Task)}

This questionnaire is meant to be completed in the course of your dictionary consultation. Answer the following questions after you have finished each sentence.

\section{Noun (}

1. On ending the search, how do you feel?
A. Sure that my decision was correct
(go to Questions 2 to 5)
B. Not sure whether my decision was correct
(go to Questions 6 to 8 )
C. I don't think I got the relevant info from the dictionary
(go to Questions 9 to 11 )

2. From which part of the dictionary entry did you find the information you wanted to look for? You can choose more than one.
A. English Definitions
B. English Examples
C. Chinese translations of definitions
D. Chinese translations of examples
E. Codes/Abbreviations
F. Special features (e.g. bold, italics, etc.)
G. Others (please specify: )

3. Write out the definitions, examples, codes/abbreviations, etc. which led you to your decision. If you used different definitions, examples, etc. for the three different sentences (i.e. A, B or C), please specify clearly which definitions, etc. are for which sentence.

4. How did your answer to Question 3 show you that your decision should be correct? Please specify the sentences (i.e. A, B, or C) you are discussing if necessary.

5. Is there any other information from the entry (other than your answer to Q.4) which showed you that the other options should be incorrect? If so, what? 
6. Which of the following helped you make your decision? You can choose more than one.
A. English Definitions
B. English Examples
C. Chinese translations of definitions
D. Chinese translations of examples
E. Codes/Abbreviations
F. Special features (e.g. bold, italics, etc.)
G. Others (please specify:

7. Write out the definitions, examples, codes/abbreviations, etc. which led you to your decision. If you used different definitions, examples, etc. for the three different sentences (i.e. A, B or C), please specify clearly which definitions, etc. are for which sentence.

8. Why were you doubtful about your decision? Please specify the sentences (i.e. A, B, or C) you are discussing if necessary.

(Please continue by answering Questions 12-17)

9. Did you consult the following information during the search?
A. English Definitions
Yes/No
B. English Examples
Yes/No
C. Chinese translations of definitions
Yes/No
D. Chinese translations of examples
Yes/No
E. Codes/Abbreviations
Yes/No
F. Special features (e.g. bold, italics, etc.)
Yes/No
G. Others (please specify:

10. What difficulties did you encounter when doing the search? Please specify the sentences (i.e. A, $B$, or C) you are discussing if necessary. 
11. How did you make your final decision? Please specify the sentences (i.e. A, B, or C) you are discussing if necessary.

(Please continue by answering Questions 12-17)

12. How would you rank the overall usefulness of the English definitions in doing the search? (Please circle the answer.)

$\begin{array}{llll}\text { Very useful } & \text { Useful } & \text { Of little use } & \text { Of no use } \\ 4 & 3 & 2 & 1\end{array}$

13. How would you rank the overall usefulness of the English examples in doing the search? (Please circle the answer.)

$\begin{array}{llll}\text { Very useful } & \text { Useful } & \text { Of little use } & \text { Of no use } \\ 4 & 3 & 2 & 1\end{array}$

14. How would you rank the overall usefulness of the Chinese translations of the definitions in doing the search? (Please circle the answer.)

$\begin{array}{llll}\text { Very useful } & \text { Useful } & \text { Of little use } & \text { Of no use } \\ 4 & 3 & 2 & 1\end{array}$

15. How would you rank the overall usefulness of the Chinese translations of the examples in doing the search? (Please circle the answer.)

$\begin{array}{llll}\text { Very useful } & \text { Useful } & \text { Of little use } & \text { Of no use } \\ 4 & 3 & 2 & 1\end{array}$

16. How would you rank the overall usefulness of the codes and abbreviations (e.g. U, sing) in doing the search? (Please circle the answer.)
Very useful
Useful
Of little use
Of no use
4
3
2
1

17. How would you rank the overall usefulness of the special features (e.g. bold) in doing the search? (Please circle the answer.)

$\begin{array}{llll}\text { Very useful } & \text { Useful } & \text { Of little use } & \text { Of no use } \\ 4 & 3 & 2 & 1\end{array}$

$$
\begin{gathered}
-\quad \text { End of Current Questionnaire }- \\
-\quad \text { Thank you }-
\end{gathered}
$$

